\title{
KSHV/HHV8-Associated Lymphoproliferative Disorders: Lessons Learnt from People Living with HIV
}

\author{
Mark Bower $^{1}$ and Antonino Carbone ${ }^{2, * \mathbb{D}}$ \\ 1 Department of Oncology and National Centre for HIV Malignancy, Chelsea \& Westminster Hospital \\ London SW10 9NH, UK; m.bower@imperial.ac.uk \\ 2 Department of Pathology, Centro di Riferimento Oncologico di Aviano (CRO), Istituto di Ricovero e Cura a \\ Carattere Scientifico (IRCCS), Via F. Gallini 2, I-33081 Aviano, Italy \\ * Correspondence: acarbone@cro.it
}

check for updates

Citation: Bower, M.; Carbone, A. KSHV/HHV8-Associated Lymphoproliferative Disorders: Lessons Learnt from People Living with HIV. Hemato 2021, 2, 703-712. https:/ / doi.org/10.3390/hemato2040047

Academic Editors: Anna Sureda and Annunziata Gloghini

Received: 11 October 2021

Accepted: 22 November 2021

Published: 24 November 2021

Publisher's Note: MDPI stays neutral with regard to jurisdictional claims in published maps and institutional affiliations.

Copyright: (c) 2021 by the authors. Licensee MDPI, Basel, Switzerland. This article is an open access article distributed under the terms and conditions of the Creative Commons Attribution (CC BY) license (https:/ / creativecommons.org/licenses/by/ $4.0 /)$.

\begin{abstract}
In 1992, Kaposi sarcoma herpesvirus (KSHV/HHV8) was discovered and identified as the causative agent for Kaposi sarcoma. Subsequently, the presence of this virus has been detected in a number of lymphoproliferative disorders in people living with HIV (PLWH), including: KSHVassociated multicentric Castleman disease, primary effusion lymphoma, KSHV-positive diffuse large B-cell lymphoma, and germinotropic lymphoproliferative disorder. Each of these rare entities has subsequently been diagnosed in HIV-negative individuals. The recognition of some of these KSHV/HHV8-associated lymphoproliferative disorders has led to their inclusion in the WHO classification of lymphomas in 2008 and the revision of 2016; however, further revision is under way to update the classification. The relatively recent recognition of these lymphoproliferative disorders and their low incidence, particularly in the HIV-negative population, means that there is little published evidence and consensus on their clinical features and management. The publication of a new WHO classification of lymphomas should yield diagnostic clarity, providing an impetus for retrospective case series and prospective clinical trials in these KSHV/HHV8-associated lymphoproliferative disorders.
\end{abstract}

Keywords: lymphomas in PLWH; KSHV/HHV8; EBV; lymphoma classification; management; cART

\section{Introduction}

On 5 June 1981, a report in the Mortality Morbidity Weekly Report (MMWR) of clusters of Pneumocystis pneumonia heralded the AIDS epidemic. Just one month later, on 3 July, a headline on the front page of the New York Times read "Rare cancer seen in 41 homosexuals". It subsequently became apparent that the incidence of Kaposi sarcoma (KS) was increased many thousands of times amongst people living with HIV (PLWH). An epidemiological investigation of Kaposi sarcoma amongst PLWH by Dame Valerie Beral and Harold Jaffe in 1990 pointed to a sexually transmitted infection [1]. In 1994, the novel oncogenic herpes virus known as Kaposi sarcoma herpesvirus (KSHV), or Human herpesvirus 8 (HHV8), was discovered by Yuan Chang and her husband Patrick Moore [2]. Thus, the search for and discovery of this novel oncogenic herpesvirus was led by the clinical observation and scientific analysis of the distribution of KS amongst PLWH.

The evidence that KSHV / HHV8 plays a causal role in the pathogenesis of KS followed shortly after its discovery. Firstly, KSHV/HHV8 is detectable in the malignant spindle cells of all forms of KS, whether associated with HIV infection, allograft recipients, or classical or endemic forms of KS. Secondly, molecular evaluation revealed that $\mathrm{KSHV} / \mathrm{HHV} 8$ is monoclonal in KS lesions, indicating that KSHV / HHV8 infection precedes the clonal expansion of KS spindle cells [3]. Thirdly, an elegant study demonstrated that the presence of KSHV / HHV8 in the blood of PLWH, prior to the introduction of combination antiretroviral therapy, predicts the subsequent development of KS [4]. Fourthly, the global distribution of KSHV/HHV8 mirrors the prevalence of KS. Finally, the KSHV/HHV8 genome encodes 
around 90 genes, along with multiple non-coding RNAs, including microRNAs. Several of these viral genes have been pirated from host cells over millennia of co-evolution and possess potentially oncogenic functions.

Following the identification of a causal role for KSHV/HHV8 in KS, the virus was linked to a number of lymphoproliferative diseases. In 1995, the presence of KSHV/HHV8 was detected in a form of plasmablastic multicentric Castleman disease, seen most frequently in PLWH [5]. Similarly, and around the same time, KSHV/HHV8-often in combination with Epstein Barr virus (EBV)—was linked to primary effusion lymphoma (PEL), which was also known as body cavity lymphoma [6,7]. Recent iterations of the WHO classification of haematological malignancy have included $\mathrm{KSHV} / \mathrm{HHV} 8$-associated diffuse large B-cell lymphomas, which have frequently arisen on a background of KSHV/HHV8-associated multicentric Castleman disease. More recently, in 2002, KSHV / HHV8-along with EBVwas identified in the rare entity germinotropic lymphoproliferative disorder (GLPD) [8]. Interestingly, whilst most KSHV/HHV8-associated lymphoproliferative disorders occur more frequently in PLWH, solid organ allograft recipients, and those from KSHV /HHV8 endemic areas, GLPD is most commonly seen in immunocompetent individuals.

Without the HIV pandemic, the discovery of KSHV / HHV8 would almost certainly have been delayed and the recognition of these KSHV/HHV8-associated lymphoproliferations would undoubtedly have been postponed; although, it is noteworthy that all forms of KSHV / HHV8-associated lymphoproliferations have been described in HIV-negative individuals. The purpose of the review is to analyse KSHV/HHV8-associated lymphoproliferations, considering how oncogenic herpesviruses contribute to the development of lymphomas. Based on the knowledge of these entities, the WHO classification of lymphomas considered the immunodeficiency-related lymphoproliferations and included the spectrum of KSHV / HHV8- and EBV-related disorders in PLWH, as well as in HIV-negative individuals.

\section{Pathological and Clinical Features}

Tables 1 and 2 show the immunophenotypic markers, virologic associations, and genetic markers of these lymphoproliferative disorders (MCD, PEL, KSHV+DLBCL, and GLPD). Co-infection of KSHV/HHV8 with EBV in tumour cells is present in only two lymphoproliferative disorders, namely PEL and GLPD. These disorders are very different from each other in terms of malignancy (malignant PEL, non-malignant GLPD), aggressiveness, and type of affected people (immunocompromised PEL, immunocompetent GLPD). KSHV/HHV8-related diseases in HIV-positive and HIV-negative subjects are morphologically indistinguishable, but their incidence is higher in PLWH than in the general population.

Table 1. Pathologic spectrum and immunophenotypic markers in KSHV/HHV8-MCD, PEL, KSHV/HHV8-DLBCL, and GLPD.

\begin{tabular}{ccccc}
\hline & CD20 & IRF4/MUM1 & CD138 & Other Positive Cell Markers \\
\hline Classic PEL & Negative & Positive & Positive & CD30, CD31, CD71, EMA \\
Solid PEL & $\begin{array}{c}\text { Negative } \\
\text { Positive }\end{array}$ & Positive & Positive & CD30, EMA \\
KSHV / HHV8-MCD-DLBCL & Positive & Positive & Lambda light chain, CD45 \\
KSHV /HHV8-MCD & Negative & Positive & Negative & CD38, IgM, Lambda light chain \\
GLPD & Negative & Positive & Positive & Monotypic light chain \\
\hline
\end{tabular}

Abbreviations: DLBCL—diffuse large B-cell lymphoma; NOS; PEL—primary effusion lymphoma; MCD—multicentric Castleman disease; GLPD—germinotropic lymphoproliferative disorder. Modified and adapted from Carbone et al. $[9,10]$. 
Table 2. Virologic association, and genetic features in KSHV/HHV8-MCD, PEL, KSHV/HHV8-DLBCL, and GLPD.

\begin{tabular}{cccc}
\hline & $\begin{array}{c}\text { EBV Infection } \\
\text { (Frequency) }\end{array}$ & $\begin{array}{c}\text { KSHV/HHV8 } \\
\text { Infection }\end{array}$ & Genetic Features \\
\hline Classic PEL & $\begin{array}{c}\text { Positive } \\
(80-100 \%)\end{array}$ & $\begin{array}{c}\text { Positive } \\
(100 \%)\end{array}$ & $\begin{array}{c}\text { Complex karyotype, no } \\
\text { recurrent translocation, Tp53 } \\
\text { and } R \text { AS rarely mutated }\end{array}$ \\
Solid PEL & Positive & $\begin{array}{c}\text { Positive } \\
(100 \%)\end{array}$ & $\begin{array}{c}\text { Occasional p53 positive cells } \\
\text { KSHV / HHV8-MCD- }\end{array}$ \\
DLBCL & Negative & $\begin{array}{c}\text { Positive } \\
(100 \%)\end{array}$ & $\begin{array}{c}\text { Myc rearrangement, TP53 } \\
\text { point mutation }\end{array}$ \\
KSHV /HHV8-MCD & Negative & $\begin{array}{c}\text { Positive } \\
(100 \%)\end{array}$ & \\
GLPD & Positive & Positive & \\
& $(100 \%)$ & $(100 \%)$ & \\
\hline
\end{tabular}

Abbreviations: DLBCL—diffuse large B-cell lymphoma; PEL—primary effusion lymphoma; MCD—multicentric Castleman disease; GLPD—germinotropic lymphoproliferative disorder; EBV—Epstein Barr Virus; KSHV/HHV8Kaposi sarcoma-associated herpesvirus. Modified and adapted from Carbone et al. [9,10].

\subsection{KSHV/HHV8-Associated Multicentric Castleman Disease (KSHV/HHV8-MCD)}

MCD is a generalized lymphoproliferative disease [11] which may display in the lymphoid tissues' interfollicular plasmacytosis or rich intrafollicular or perifollicular vascularity, with hyalinization. KSHV/HHV8-MCD is a plasmablastic variant of MCD (Figure 1) [12,13].
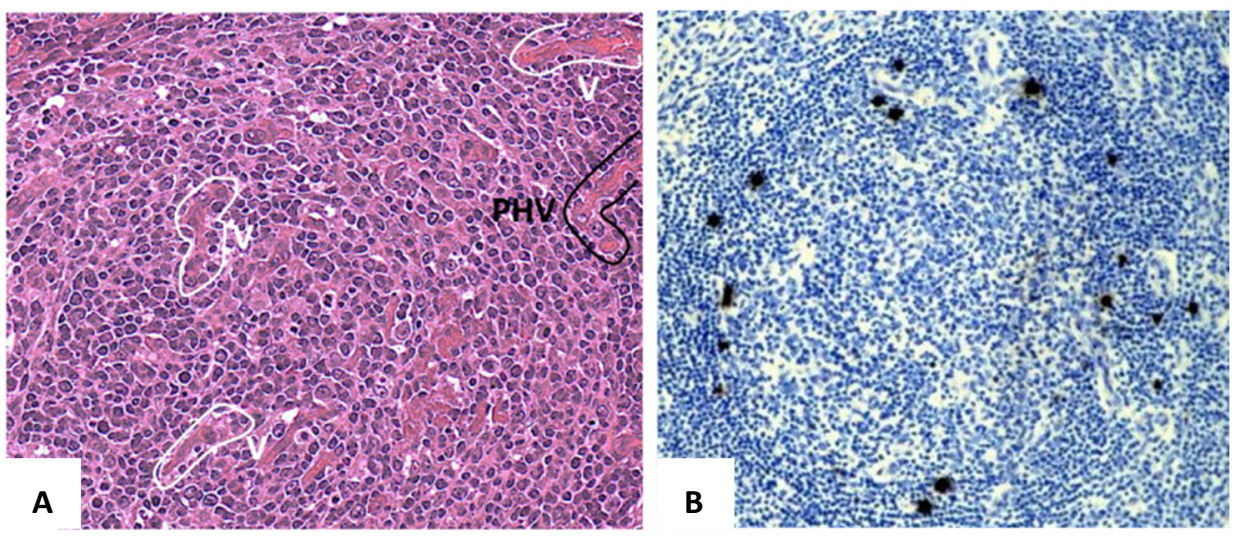

Figure 1. KSHV/HHV8-associated MCD. (A) There is a marked intrafollicular vascular proliferation (V). The lymphoid follicle also has typical penetrating hyalinised vessels (PHV). (B) In the follicular mantle, some large atypical cells, consistent with plasmablasts, are positive for KSHV/HHV8 viral IL-6. Magnification $\times 20(\mathbf{A}, \mathbf{B})$.

Disorders that morphologically overlap with MCD include follicular hyperplasia, NOS, HIV-associated lymphadenopathy, autoimmune disorders, HL, and plasmacytoma [14].

Patients with KSHV/HHV8-MCD present with marked constitutional symptoms, generalised lymphadenopathy, and splenomegaly. Fever, night sweats, and weight loss are common and up to half the patients have cutaneous or lymph node Kaposi sarcoma. Autoimmune haemolytic anaemia and thrombocytopenia are frequent, alongside hypergammaglobulinemia and hypoalbuminemia. Approximately $10 \%$ have features of haemophagocytosis and $10 \%$ have pulmonary involvement with ground-glass pneumonitis. KSHV/HHV8-MCD is a relapsing and remitting illness and two clinical criteria have been devised for establishing a diagnosis of active MCD, one from the French ANRS (Agence Nationale de Recherche sur le SIDA) 117 CastlemaB trial group and one from the National Cancer Institute (NCI) $[15,16]$ (see Table 3). The French ANRS definition requires the following: raised serum C-reactive protein (CRP) (in the absence of any other cause), 
pyrexia, and at least 3 of 12 clinical features [15]. The National Cancer Institute (NCI) scheme requires the following: raised serum CRP, at least one clinical symptom, and one laboratory abnormality probably or definitely attributed to MCD [16]. The serum CRP cut-off is higher in the French $(>20 \mathrm{mg} / \mathrm{L})$ than in the US $(>3 \mathrm{mg} / \mathrm{L})$ scheme. Although the two systems have been compared in an independent patient population of 75 cases [17], one of the simplest and most reliable laboratory markers of active KSHV/HHV8-MCD is a markedly elevated blood KSVH level.

Table 3. Comparison of French ANRS (Agence Nationale de Recherche sur le SIDA) 117 CastlemaB trial group and the National Cancer Institute (NCI) criteria used to define a flare of KSHV-associated multicentric Castelman disease [15,16].

\begin{tabular}{cc}
\hline ANRS Criteria & NCI Criteria \\
\hline Fever & Fatigue CTAE grade $>1$ \\
C-reactive protein $>20 \mathrm{mg} / \mathrm{L}$ in the absence of any & Fever or night sweats \\
other aetiology & Weight loss \\
Peripheral lymphadenopathy & Respiratory symptoms \\
Enlarged spleen & Gastrointestinal symptoms \\
Oedema & Neurological symptoms \\
Pleural effusion & Oedema or effusion \\
Ascites & Xerostomia \\
Cough & Rash \\
Nasal obstruction & \\
Xerostomia & \\
Rash & Anaemia $(\mathrm{Hb}<12 \mathrm{~g} / \mathrm{dL})$ \\
Central neurologic symptoms & Thrombocytopenia $\left(<100 \times 10^{9} / \mathrm{L}\right)$ \\
Autoimmune haemolytic anaemia & Hypoalbuminemia $(<35 \mathrm{~g} / \mathrm{L})$ \\
& Serum CRP $>3 \mathrm{mg} / \mathrm{L}$ \\
\hline
\end{tabular}

\subsection{Primary Effusion Lymphoma (PEL), Classic, and Solid Variants}

PEL is an AIDS-a disease and one third of patients have coincidental Kaposi sarcoma. There is a pathological or clinical overlap between PEL, KSHV/HHV8-MCD, and $\mathrm{KSHV} / \mathrm{HHV} 8$ inflammatory cytokine syndrome (KICS). KICS is a condition characterized by elevated levels of viral proteins and cytokines, such as MCD. However, KICS is not associated with lymphadenopathy. PEL tumour cells, both in classic form and in solid variant, display a plasmablastic or anaplastic morphology, are positive for latency-associated nuclear antigen 1 (LANA1) (Figure 2), and are often positive for EBV/EBER. They are frequently positive for CD45, CD38, CD138, BLIMP1, VSc38, MUM1, CD30, and EMA.

PEL was first described in 1989 in the context of PLWH [18] and the link with $\mathrm{KSHV} / \mathrm{HHV} 8$ was discovered in 1995 [6]. As originally defined, PEL is a large B-cell lymphoma presenting in pleural, peritoneal, or pericardial effusions. These effusions are not usually associated with lymphoma masses; although, up to a third of patients have co-existing Kaposi sarcoma. In the early case series of PEL among PLWH, patients were usually young men who have sex with men (MSM) with low CD4 cell counts and the PEL lymphoma cells were co-infected with both KSHV/HHV8 and EBV [19]. Subsequently, PEL was described in solid organ transplant recipients [20] as well as elderly HIV-negative individuals who live in areas of high KSHV/HHV8 prevalence [21,22].

A decade after the original description of PEL, the category was expanded to include extra-cavity solid lymphomas with the same morphology, immunophenotype, and virology [23,24]. These solid PEL have been described in both PLWH and HIV-negative individuals and often present with extra-nodal disease. 

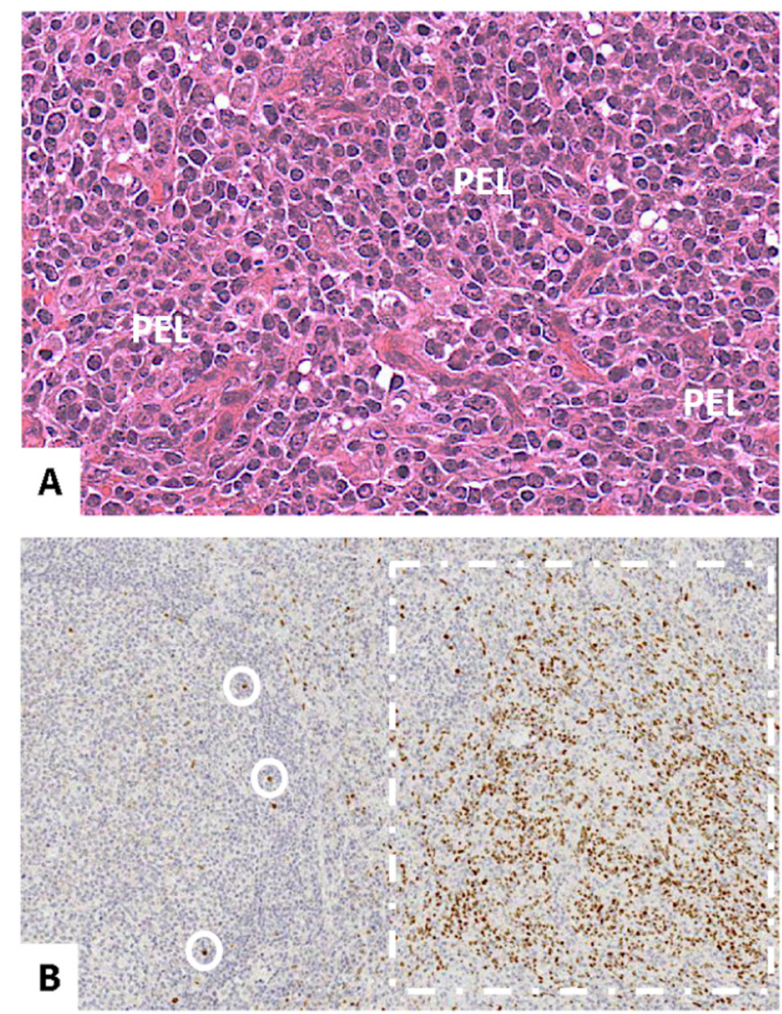

Figure 2. KSHV/HHV8-associated MCD and solid PEL. (A) The figure shows large atypical lymphoid cells with plasmablastic morphology, consistent with solid PEL. The tumour cells are negative for CD20 and variably positive for CD138 and CD30 (not shown). (B) This lymphoma is involving the lymph node in the interfollicular zone of the lymph node (dashed). Neoplastic cells are positive for LANA. In the follicular mantle, some large, atypical cells, consistent with plasmablasts, are also positive for LANA (circled). Magnification $\times 40$ (A), $\times 20$ (B).

A recent meta-analysis included 301 cases of whom 181 (63\%) occurred in PLWH [25]. Over $90 \%$ PEL cases occurred in men, including $85 \%$ in HIV-negative individuals and the median age was 55 years (43 years in PLWH and 73 years in HIV-negative individuals). Almost half the cases involved the pleural cavity followed by abdominal cavity $(14 \%)$ and pericardium ( $8 \%$ ) and $28 \%$ had involvement of multiple body cavities.

KSHV/HHV8-positive diffuse B-large cell lymphoma, NOS.

$\mathrm{KSHV}$ /HHV8-positive diffuse large B-cell lymphoma, NOS is a relatively new lymphoma category, usually arising in association with MCD and HIV infection. The tumour cells display plasmablastic features and are usually positive for CD45 or CD20 and express terminal B-cell differentiation markers, including MUM1. They are often negative for $\mathrm{EBV} / \mathrm{EBER}$.

Many of these lymphomas arise in the context of KSHV/HHV8-MCD in PLWH. The risk of lymphoma in patients with KSHV/HHV8-MCD is extremely high and may affect up to one in five patients [26,27], and in one series, lymphoma was the most frequent cause of death [28]. In many cases, the lymphomas were positive for KSVH and most frequently were classified as primary effusion lymphomas and large B-cell lymphomas (KSHV /HHV8-positive DLBCL or NOS in the 2016 WHO classification), both with poor prognoses. KSHV/HHV8-DLBCL is most commonly present with lymphadenopathy and splenomegaly; although, extra-nodal involvement does occur uncommonly. The limited number of cases reported and (to some extent) the relatively recent recognition of this sub-classification means that not only is the optimal therapy uncertain, but the prognosis is also unclear; although, it is a widely held view that the prognosis is worse than KSHV/HHV8-negative DLBCL in the same HIV-positive population. 


\subsection{KSHV/HHV8-Positive Germinotropic Lymphoproliferative Disorder (GLPD)}

GLPD usually presents with localized lymphadenopathy, often without immunodeficiency. A plasmablastic proliferation is confined to expanded germinal centres, which are positive for cytoplasmic monotypic light chain, CD38, MUM1, KSHV/HHV8 viral IL6, LANA1, and EBV/EBER (Figures 3 and 4).
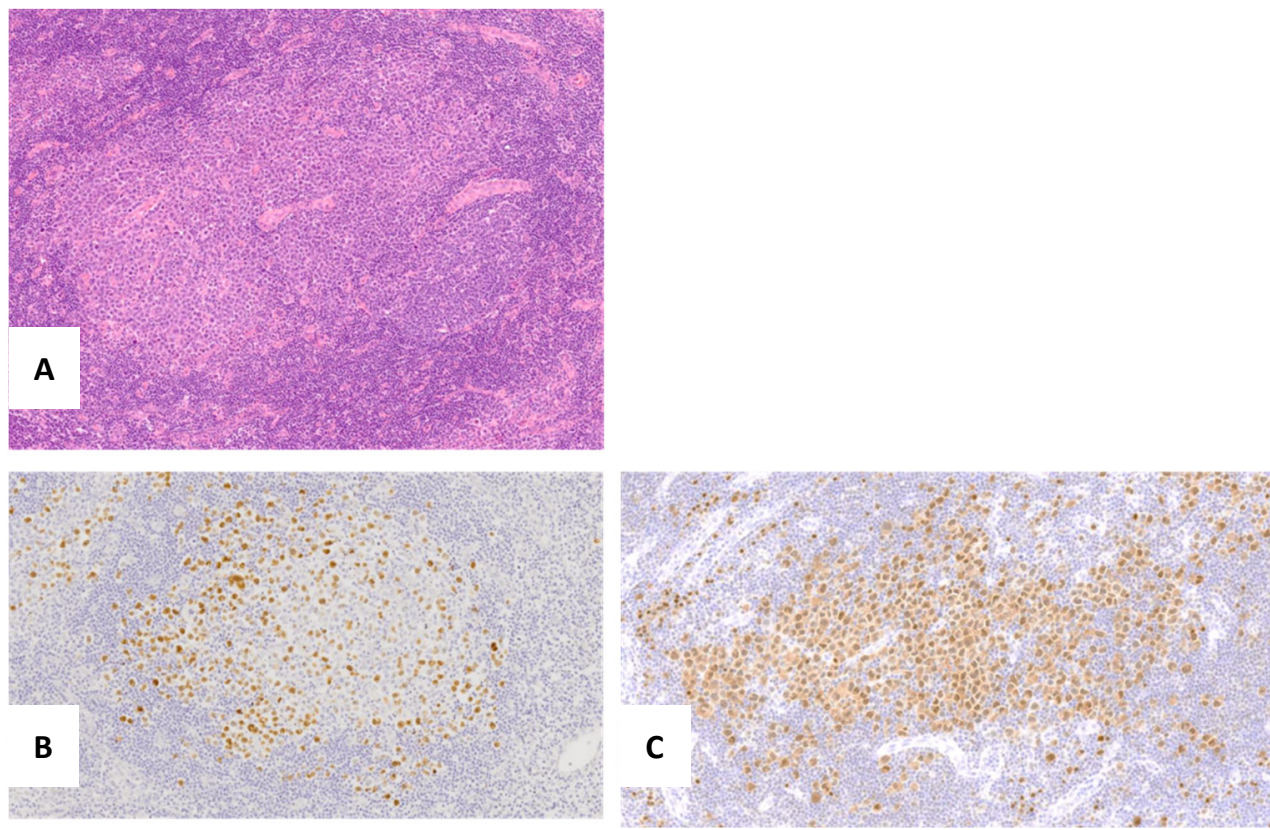

Figure 3. Germinotropic lymphoproliferative disorder. (A) The Hematoxylin and Eosin stain shows aggregates of plasmablasts with the involved germinal centres. (B) Plasmablasts are positive for MUM1. (C) In situ hybridization for EBV-encoded RNA (EBER) shows EBV infection.

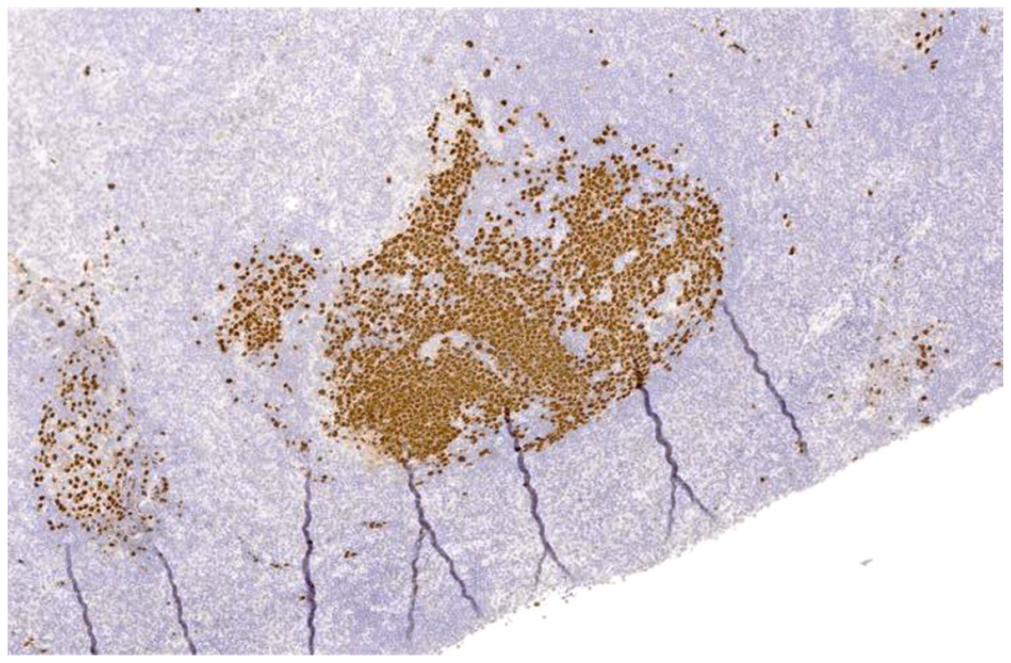

Figure 4. Germinotropic lymphoproliferative disorder. Immunohistochemical stain for KSHV/HHV8encoded LANA shows co-infection of KSHV/HHV8 in the plasmablasts, within the involved germinal centres.

GLPD is a very rare disease with an indolent clinical course. A systematic review of the published literature in 2020 only identified 19 cases [29], only 5 of which were those of HIV-seropositive individuals. The described cases occurred mostly in middle aged men (68\% male, mean age 58) and all presented with nodal involvement. Lymphadenopathy was present in all cases but fewer than half had constitutional symptoms and most of those who did were PLWH. 


\section{Treatment and Outcome}

\section{1. $K S H V / H H V 8-M C D$}

The clinical care of PLWH who developed KSHV/HHV8-MCD was revolutionised in 2007 by the publication of two prospective open-label phase 2 clinical studies, that established the efficacy of rituximab $[15,30]$. Subsequently, it was established that for patients with life-threatening organ failure or the presence of concurrent Kaposi sarcoma (KS), the addition of chemotherapy to rituximab was required. In general etoposide is the additional drug of choice for patients with life-threating disease, whilst pegylated liposomal doxorubicin is usually added to rituximab if there is concurrent KS. Three large European cohort studies have described the medium-term outcomes of this approach using rituximab-based immunochemotherapy in a total of 249 patients, yielding 5 year overall survival in excess of $90 \%[26,28,31]$. Despite the high response rates and good longterm survival following rituximab-based treatment, relapse is frequent and can usually be salvaged with a further course of rituximab [28].

Even though rituximab-based therapy is highly successful in KSHV/HHV8-MCD, other management strategies have been investigated, including the use of anti-herpes virus therapies. Anti-herpes virus drugs target viral replication, and for this reason have very limited success in KS where the majority of KSVH is latent. However, in KSHV/HHV8MCD there are high levels of lytic replication of KSHV / HHV8 and this makes the approach with anti-herpes agents attractive. Several small studies using anti-virals have reported efficacy in KSHV/HHV8-MCD, but in most cases the responses were brief [32-36]. A combination of valganciclovir and zidovudine has been most widely studied with a recent publication reporting 5 year progression-free survival (PFS) of just $26 \%$ as first line therapy but a more promising $87 \% 5$ year PFS, when used as maintenance after rituximab-based immunochemotherapy for 10 patients, compared with a figure of $62 \%$ for 16 patients who did not receive maintenance [37]. It is thought that KSHV/HHV8 encoded vIL-6, an early lytic gene of KSHV/HHV8, contributes to the pathogenesis of $\mathrm{KSHV} / \mathrm{HHV} 8$ MCD. This virokine binds to the gp80 subunit of the IL-6 receptor, which is the target of the monoclonal antibody tocilizumab. However, single agent tocilizumab achieved only transient responses in just 5 of $8 \mathrm{HIV}$ patients with KSHV/HHV8-MCD [38].

\subsection{PEL}

The treatment of PEL in both PLWH and HIV-negative individuals is not based on clinical trial evidence. Nevertheless, there is a general consensus that patients should be treated with multi-agent chemotherapy, along with combination antiretroviral therapy, opportunistic infection prophylaxis, and careful consideration of the potential pharmacological interactions (if HIV seropositive) [39]. The most widely employed regimens are dose-adjusted EPOCH (etoposide, prednisolone, vincristine, cyclophosphamide, doxorubicin) or CHOP (cyclophosphamide, doxorubicin, vincristine, prednisolone). Rituximab may be added to these regimens if the tumour expresses CD20, although this is uncommon. The prognosis is pretty poor, with fewer than $50 \%$ alive at 1 year [40,41]; although, earlier series reported an even worse prognosis [42,43]. In a meta-analysis of 301 patients from the literature, systemic chemotherapy was associated with an improved median survival (8 months vs $1.8 \mathrm{~m}$ ). Furthermore, in this analysis, peritoneal involvement and elevated serum LDH were associated with worse prognosis, whilst pericardial involvement carried a lower risk of death. Interestingly, HIV status did not influence prognosis [25].

The poor outcomes have led investigators to explore the roles of molecular-targeting therapies in PEL, including immunomodulatory drugs (thalidomide, lenalidomide, pomalidomide), proteosome inhibitors (bortezomib), and monoclonal antibodies targeting CD30 (brentuximab) and CD38 (daratumumab), but with limited success [44].

\section{3. $\mathrm{KSHV} / \mathrm{HHV} 8$-Associated DLBCL}

Again, there is no consensus regarding optimal treatment of these tumours and prognosis is poor [45]. Either CODOX-M/IVAC (as used for Burkitt lymphoma and 
leukaemia) or dose-adjusted EPOCH are frequently used, whilst CHOP chemotherapy is generally considered inadequate [39].

\subsection{GLPD}

With so few cases described in the literature it is impossible to be clear about the optimal therapeutic strategies in GLPD. Combination chemotherapy with $\mathrm{CHOP}$ or EPOCH has been administered to seven patients and five have achieved remission. However, a less aggressive approach was taken in ten patients with monitoring, surgery, or radiotherapy but no systemic anticancer therapy. The very limited data suggests that GLPD may be a more indolent disorder than other KSHV/HHV8-associated lymphoproliferations [8,29,46].

\section{Conclusions}

Following the discovery of KSHV/HHV8, it was quickly identified in MCD and subsequently in PEL, some PBL, and in the rare cases of these diseases that occur in HIVnegative individuals. The pathogenetic role of KSHV/HHV8 in these lymphoproliferations is uncertain; although, the virus encodes many potential oncogenes and tumour suppressor genes, which could contribute, though many are lytic antigens. The increasing recognition of these KSHV/HHV8 lymphoproliferative disorders and their clear identification in the WHO classification has driven forward knowledge of their clinical behaviour and treatment. Thus, the recognition of KSHV/HHV8-MCD has resulted in established clinical criteria, clinical management trials, and consensus treatment protocols that have led to improvements in survival. To a lesser extent, these advances have also been seen for PEL, which was first included in the WHO classification in 2001. It is hoped that the inclusion of KSHV /HHV8-associated DLBCL in the 2016 revision and the inclusion of GLPD in future classifications will similarly lead to greater recognition, better treatments, and survival benefits for patients.

Funding: This research received no external funding.

Conflicts of Interest: The authors declare no conflict of interest.

\section{References}

1. Beral, V.; Peterman, T.A.; Berkelman, R.L.; Jaffe, H.W. Kaposi's sarcoma among persons with AIDS: A sexually transmitted infection? Lancet 1990, 335, 123-128. [CrossRef]

2. Chang, Y.; Cesarman, E.; Pessin, M.S.; Lee, F.; Culpepper, J.; Knowles, D.M.; Moore, P.S. Identification of herpesvirus-like DNA sequences in AIDS-associated Kaposi's sarcoma. Science 1994, 266, 1865-1869. [CrossRef] [PubMed]

3. Judde, J.G.; Lacoste, V.; Briere, J.; Kassa-Kelembho, E.; Clyti, E.; Couppié, P.; Buchrieser, C.; Tulliez, M.; Morvan, J.; Gessain, A. Monoclonality or oligoclonality of human herpesvirus 8 terminal repeat sequences in Kaposi's sarcoma and other diseases. $J$. Natl. Cancer Inst. 2000, 92, 729-736. [CrossRef] [PubMed]

4. Whitby, D.; Boshoff, C.; Hatzioannou, T.; Weiss, R.A.; Schulz, T.F.; Howard, M.R.; Brink, N.S.; Tedder, R.S.; Tenant-Flowers, M.; Copas, A. Detection of Kaposi's sarcoma-associated herpesvirus (KSHV) in peripheral blood of HIV-infected individuals predicts progression to Kaposi's sarcoma. Lancet 1995, 364, 799-802. [CrossRef]

5. Soulier, J.; Grollet, L.; Oksenhendler, E.; Cacoub, P.; Cazals-Hatem, D.; Babinet, P.; d'Agay, M.F.; Clauvel, J.P.; Raphael, M.; Degos, L. Kaposi's sarcoma-associated herpesvirus-like DNA sequences in multicentric Castleman's disease. Blood 1995, 86, 1276-1280. [CrossRef] [PubMed]

6. Cesarman, E.; Chang, Y.; Moore, P.S.; Said, J.W.; Knowles, D.M. Kaposi's sarcoma-associated herpesvirus-like DNA sequences in AIDS-related body-cavity-based lymphomas. N. Engl. J. Med. 1995, 332, 1186-1191. [CrossRef] [PubMed]

7. Nador, R.G.; Cesarman, E.; Chadburn, A.; Dawson, D.B.; Ansari, M.Q.; Sald, J.; Knowles, D.M. Primary effusion lymphoma: A distinct clinicopathologic entity associated with the Kaposi's sarcoma-associated herpes virus. Blood 1996, 88, 645-656. [CrossRef] [PubMed]

8. Du, M.-Q.; Diss, T.C.; Liu, H.; Ye, H.; Hamoudi, R.A.; Cabeçadas, J.; Dong, H.Y.; Harris, N.L.; Chan, J.K.C.; Rees, J.W.; et al. KSHVand EBV-associated germinotropic lymphoproliferative disorder. Blood 2002, 100, 3415-3418. [CrossRef] [PubMed]

9. Carbone, A.; Vaccher, E.; Gloghini, A.; Pantanowitz, L.; Abayomi, A.; de Paoli, P.; Franceschi, S. Diagnosis and management of lymphomas and other cancers in HIV-infected patients. Nat. Rev. Clin. Oncol. 2014, 11, 223-238. [CrossRef]

10. Carbone, A.; Vaccher, E.; Gloghini, A. Hematological cancers in individuals infected by HIV. Blood 2021. [CrossRef]

11. Kessler, E. Multicentric giant lymph node hyperplasia. A report of seven cases. Cancer 1985, 56, 2446-2451. [CrossRef] 
12. Van Rhee, F.; Oksenhendler, E.; Srkalovic, G.; Voorhees, P.; Lim, M.; Dispenzieri, A.; Ide, M.; Parente, S.; Schey, S.; Streetly, M.; et al. International evidence-based consensus diagnostic and treatment guidelines for unicentric Castleman disease. Blood Adv. 2020, 4, 6039-6050. [CrossRef] [PubMed]

13. Wang, H.-W.; Pittaluga, S.; Jaffe, E.S. Multicentric Castleman disease: Where are we now? Semin. Diagn. Pathol. 2016, 33, $294-306$. [CrossRef] [PubMed]

14. Vega, F.; Miranda, R.N.; Medeiros, L.J. KSHV/HHV8-positive large B-cell lymphomas and associated diseases: A heterogeneous group of lymphoproliferative processes with significant clinicopathological overlap. Mod. Pathol. 2019, 33, 18-28. [CrossRef] [PubMed]

15. Gérard, L.; Bérezné, A.; Galicier, L.; Meignin, V.; Obadia, M.; de Castro, N.; Jacomet, C.; Verdon, R.; Madelaine-Chambrin, I.; Boulanger, E. Prospective Study of Rituximab in Chemotherapy-Dependent Human Immunodeficiency Virus Associated Multicentric Castleman's Disease: ANRS 117 CastlemaB Trial. J. Clin. Oncol. 2007, 25, 3350-3356. [CrossRef] [PubMed]

16. Uldrick, T.S.; Polizzotto, M.; Yarchoan, R. Recent advances in Kaposi sarcoma herpesvirus-associated multicentric Castleman disease. Curr. Opin. Oncol. 2012, 24, 495-505. [CrossRef] [PubMed]

17. Bower, M.; Pria, A.D.; Coyle, C.; Nelson, M.; Naresh, K. Diagnostic Criteria Schemes for Multicentric Castleman Disease in 75 Cases. JAIDS J. Acquir. Immune Defic. Syndr. 2014, 65, e80-e82. [CrossRef]

18. Knowles, D.M.; Inghirami, G.; Ubriaco, A.; Dalla-Favera, R. Molecular genetic analysis of three AIDS-associated neo-plasms of uncertain lineage demonstrates their B-cell derivation and the possible pathogenetic role of the Epstein-Barr virus. Blood 1989, 73 , 792-799. [CrossRef] [PubMed]

19. Simonelli, C.; Spina, M.; Cinelli, R.; Talamini, R.; Tedeschi, R.; Gloghini, A.; Vaccher, E.; Carbone, A.; Tirelli, U. Clinical features and outcome of primary effusion lymphoma in HIV-infected patients: A single-institution study. J. Clin. Oncol. 2003, 21, 3948-3954. [CrossRef]

20. Riva, G.; Luppi, M.; Barozzi, P.; Forghieri, F.; Potenza, L. How I treat HHV8/KSHV-related diseases in posttransplant patients. Blood 2012, 120, 4150-4159. [CrossRef]

21. Said, J.W.; Tasaka, T.; Takeuchi, S.; Asou, H.; de Vos, S.; Cesarman, E.; Knowles, D.M.; Koeffler, H.P. Primary effusion lymphoma in women: Report of two cases of Kaposi's sarcoma herpes virus-associated effusion-based lymphoma in human immunodeficiency virus-negative women. Blood 1996, 88, 3124-3128. [CrossRef]

22. Ascoli, V.; Scalzo, C.C.; Danese, C.; Vacca, K.; Pistilli, A.; Coco, F.L. Human herpes virus-8 associated primary effusion lymphoma of the pleural cavity in HIV-negative elderly men. Eur. Respir. J. 1999, 14, 1231-1234. [CrossRef] [PubMed]

23. Chadburn, A.; Hyjek, E.; Mathew, S.; Cesarman, E.; Said, J.; Knowles, D.M. KSHV-Positive solid lymphomas represent an extra-cavitary variant of primary effusion lymphoma. Am. J. Surg. Pathol. 2004, 28, 1401-1416. [CrossRef]

24. Carbone, A.; Gloghini, A.; Vaccher, E.; Marchetti, G.; Gaidano, G.; Tirelli, U. KSHV/HHV-8 associated lymph node based lymphomas in HIV seronegative subjects. Report of two cases with anaplastic large cell morphology and plasmablastic immunophenotype. J. Clin. Pathol. 2005, 58, 1039-1045. [CrossRef]

25. Aguilar, C.; Laberiano, C.; Beltran, B.; Diaz, C.; Taype-Rondan, A.; Castillo, J.J. Clinicopathologic characteristics and survival of patients with primary effusion lymphoma. Leuk. Lymphoma 2020, 61, 2093-2102. [CrossRef] [PubMed]

26. Gérard, L.; Michot, J.M.; Burcheri, S.; Fieschi, C.; Longuet, P.; Delcey, V.; Meignin, V.; Agbalika, F.; Chevret, S.; Oksenhendler, E. Rituximab decreases the risk of lymphoma in patients with HIV-associated multicentric Castleman disease. Blood 2012, 119, 2228-2233. [CrossRef] [PubMed]

27. Oksenhendler, E.; Boulanger, E.; Galicier, L.; Du, M.Q.; Dupin, N.; Diss, T.C.; Hamoudi, R.; Daniel, M.T.; Agbalika, F.; Boshoff, C.; et al. High incidence of Kaposi sarcoma-associated herpesvirus-related non-Hodgkin lym-phoma in patients with HIV infection and multicentric Castleman disease. Blood 2002, 99, 2331-2336. [CrossRef]

28. Pria, A.D.; Pinato, D.; Roe, J.; Naresh, K.; Nelson, M.; Bower, M. Relapse of HHV8-positive multicentric Castleman disease following rituximab-based therapy in HIV-positive patients. Blood 2017, 129, 2143-2147. [CrossRef]

29. Zanelli, M.; Zizzo, M.; Bisagni, A.; Froio, E.; de Marco, L.; Valli, R.; Filosa, A.; Luminari, S.; Martino, G.; Massaro, F.; et al. Germinotropic lymphoproliferative disorder: A systematic review. Ann. Hematol. 2020, 99, 2243-2253. [CrossRef]

30. Bower, M.; Powles, T.; Williams, S.; Davis, T.N.; Atkins, M.; Montoto, S.; Orkin, C.; Webb, A.; Fisher, M.; Nelson, M.; et al. Brief Communication: Rituximab in HIV-Associated Multicentric Castleman Disease. Ann. Intern. Med. 2007, 147, 836-839. [CrossRef] [PubMed]

31. Hoffmann, C.; Schmid, H.; Müller, M.; Teutsch, C.; van Lunzen, J.; Esser, S.; Wolf, T.; Wyen, C.; Sabranski, M.; Horst, H.-A.; et al. Improved outcome with rituximab in patients with HIV-associated multicentric Castleman disease. Blood 2011, 118, 3499-3503. [CrossRef] [PubMed]

32. Uldrick, T.S.; Polizzotto, M.; Aleman, K.; O’Mahony, D.; Wyvill, K.M.; Wang, V.; Marshall, V.; Pittaluga, S.; Steinberg, S.M.; Tosato, G.; et al. High-dose zidovudine plus valganciclovir for Kaposi sarcoma herpesvirus-associated multicentric Castleman disease: A pilot study of virus-activated cytotoxic therapy. Blood 2011, 117, 6977-6986. [CrossRef] [PubMed]

33. Casper, C.; Nichols, W.G.; Huang, M.L.; Corey, L.; Wald, A. Remission of HHV-8 and HIV-associated multi-centric Castleman disease with ganciclovir treatment. Blood 2004, 103, 1632-1634. [CrossRef] [PubMed]

34. Oksenhendler, E.; Duarte, M.; Soulier, J.; Cacoub, P.; Welker, Y.; Cadranel, J.; Cazals-Hatem, D.; Autran, B.; Clauvel, J.P.; Raphael, M. Multicentric Castleman's disease in HIV infection: A clinical and pathological study of 20 patients. AIDS 1996, 10, 61-67. [CrossRef] [PubMed] 
35. Berezne, A.; Agbalika, F.; Oksenhendler, E. Failure of cidofovir in HIV-associated multicentric Castleman disease. Blood 2004, 103, 4368-4369. [CrossRef]

36. Senanayake, S.; Kelly, J.; Lloyd, A.; Waliuzzaman, Z.; Goldstein, D.; Rawlinson, W. Multicentric Castleman's disease treated with antivirals and immunosuppressants. J. Med. Virol. 2003, 71, 399-403. [CrossRef]

37. Ramaswami, R.; Lurain, K.; Polizzotto, M.N.; Ekwede, I.; Waldon, K.; Steinberg, S.M.; Mangusan, R.; Widell, A.; Rupert, A.; George, J.; et al. Characteristics and outcomes of KSHV-associated multicentric Castleman disease with or without other KSHV diseases. Blood Adv. 2021, 5, 1660-1670. [CrossRef]

38. Ramaswami, R.; Lurain, K.; Peer, C.J.; Serquiña, A.; Wang, V.Y.; Widell, A.; Goncalves, P.; Steinberg, S.M.; Marshall, V.; George, J.; et al. Tocilizumab in patients with symptomatic Kaposi sarcoma herpesvirus-associated multicentric Castleman disease. Blood 2020, 135, 2316-2319. [CrossRef]

39. Writing Group; Bower, M.; Palfreeman, A.; Alfa-Wali, M.; Bunker, C.; Burns, F.; Churchill, D.; Collins, S.; Cwynarski, K.; Edwards, S.; et al. British HIV Association guidelines for HIV-associated malignancies 2014. HIV Med. 2014, 15, 1-92. [CrossRef]

40. Guillet, S.; Gérard, L.; Meignin, V.; Agbalika, F.; Cuccini, W.; Denis, B.; Katlama, C.; Galicier, L.; Oksenhendler, E. Classic and extracavitary primary effusion lymphoma in 51 HIV-infected patients from a single institution. Am. J. Hematol. 2016, 91, $233-237$. [CrossRef]

41. Lurain, K.; Polizzotto, M.N.; Aleman, K.; Bhutani, M.; Wyvill, K.M.; Gonçalves, P.H.; Ramaswami, R.; Marshall, V.A.; Miley, W.; Steinberg, S.M.; et al. Viral, immunologic, and clinical features of primary effusion lymphoma. Blood 2019, 133, $1753-1761$. [CrossRef] [PubMed]

42. Olszewski, A.J.; Fallah, J.; Castillo, J.J. Human immunodeficiency virus-associated lymphomas in the antiretroviral therapy era: Analysis of the National Cancer Data Base. Cancer 2016, 122, 2689-2697. [CrossRef] [PubMed]

43. El-Fattah, M.A. Clinical characteristics and survival outcome of primary effusion lymphoma: A review of 105 patients. Hematol. Oncol. 2017, 35, 878-883. [CrossRef] [PubMed]

44. Shimada, K.; Hayakawa, F.; Kiyoi, H. Biology and management of primary effusion lymphoma. Blood 2018, 132, 1879-1888. [CrossRef] [PubMed]

45. Castillo, J.J.; Winer, E.S.; Stachurski, D.; Perez, K.; Jabbour, M.; Milani, C.; Colvin, G.; Butera, J.N. Prognostic Factors in Chemotherapy-Treated Patients with HIV-Associated Plasmablastic Lymphoma. Oncology 2010, 15, 293-299. [CrossRef] [PubMed]

46. Ronaghy, A.; Wang, H.-Y.; Thorson, J.A.; Medeiros, L.J.; Xie, Y.; Zhang, X.; Sheikh-Fayyaz, S. PD-L1 and Notch1 expression in KSHV/HHV-8 and EBV associated germinotropic lymphoproliferative disorder: Case report and review of the literature. Pathology 2017, 49, 430-435. [CrossRef] 